\title{
Neurotoxin Release from Shigella dysenteriae by Phage Infection
}

\author{
By K. LI* \\ Department of Microbiology, New York University School of Medicine \\ New York, N.Y., U.S.A.
}

(Received 23 September 1965)

\section{SUMMARY}

Shigella dysenteriae organisms of a very young culture released neurotoxin into the medium within $1 \mathrm{hr}$ after it was infected with T-phages. Two types of phage-associated enzymes were considered to be involved in this process. The first type was phage-bound enzyme, which was bound firmly with phage, worked together with phage, and depolymerized neurotoxin into smaller molecules. The second type enzyme was phage-induced lysin, so-called 'endolysin', which was separable from phage and had lytic activity on dead bacteria. The latter enzyme, however, had no direct effect on the amount of neurotoxin released from acetone-powder preparations of the bacteria into phosphate buffer, although endolysin lysed $25 \%$ of the bacteria at $30^{\circ}$ in $30 \mathrm{~min}$. Young living $S$. dysenteriae organisms did not release neurotoxin into the medium under normal conditions, whereas the acetone-powder preparations of $S$. dysenteriae, i.e. dead organisms, released neurotoxin into the medium freely under the same conditions.

\section{INTRODUCTION}

Rough strains of Shigella dysenteriae produce an exotoxin which is a neurotoxic protein, whereas smooth strains of the organisms produce both a neurotoxin and an endotoxin which is closely associated or identical with somatic $\mathbf{O}$ polysaccharide antigen (Boivin, 1940). The existence of these two toxins has been the subject of controversy for a considerable time, but abundant experimental evidence leaves little doubt that both toxins exist (Engley, 1952). Many methods for production of Shiga neurotoxin have been described (Dubos \& Geiger, 1946). Van Heyningen \& Gladstone (1953) reported the production, purification and properties of a neurotoxin of S. shigae. Sourek \& Raška (1963) purified Shiga exotoxin by preparative electrophoresis and gel filtration on Sephadex.

$\mathrm{Li}$, Barksdale \& Garmise (1961) reported that the complex of phage and Shigella dysenteriae released various biologically active macromolecules not ordinarily detected as extracellular products. The present paper explores the possible role of phage and phage-induced lysin in the release of neurotoxin by $S$. dysenteriae.

- Present address: Department of Pathology, Misericordia-Fordham Affiliation, Bronx, N.Y. 10458, U.S.A. 


\section{METHODS}

Organisms. Shigella dysenteriae wild type (strain 136-T) was isolated by Dr W. L. Barksdale from a case of Shiga dysentery in Tokyo in 1947. Strain 136-T forms smooth translucent colonies on Neopeptone agar, and is resistant to phages $T_{3}, T_{4}, T_{5}$ and $\mathrm{T}_{7}$. From strain 136-T several rough mutants have been derived; among these are mutants $136-0$ and $136-\mathbf{R}_{4}$. These rough strains are capable of adsorbing and supporting the growth of more phages of the $T$ series than was the wild type 136-T. Strain Sh 60 was obtained from Dr W. E. van Heyningen by Dr W. L. Barksdale. It is sensitive to phages $T_{2}, T_{3}, T_{4}, T_{6}$, and $T_{7}$, and is used for neurotoxin production.

Media. Tryptose agar consisted of Bactotryptose, 20 g.; glucose, 1 g.; sodium chloride, 5 g.; Bactoagar, 15 g.; thiamine hydrochloride, 0.005 g.; water to 1 l.; final $\mathrm{pH} 7 \cdot 2$; sterilized by autoclaving at $121^{\circ}$ for $15 \mathrm{~min}$. Plates were poured to the desired thickness of $5 \mathrm{~mm}$. for the agar-diffusion method. Neopeptone broth consisted of Neopeptone (Difco) $+50 \%(v / v)$ fresh beef infusion. PGT medium is the casein hydrolysate medium of Mueller \& Miller (1941) as modified by Barksdale \& Pappenheimer (1954). This medium was used for toxin production.

Bacteriophages. All phages of the $\mathrm{T}$ series were derived from stocks maintained by the late Mark H. Adams. Methods and materials for phage assay were as described by Adams (1959).

Acetone powder preparation of Shigella dysenteriae. Organisms were grown in Neopeptone broth at $37^{\circ}$ for $18 \mathrm{hr}$, washed with cold saline by centrifugation and then washed four times with 10 vol. of cold acetone. Acetone from the final wash was decanted and the organisms were dried to a white powder in vacuum. Plates for endolysin assay were prepared by adding $0.5 \mathrm{ml}$. acetone powder (suspended in saline to an opacity reading of 25 at $590 \mathrm{~m} \mu$ as measured in a Bausch \& Lomb Junior spectrophotometer) to $2.0 \mathrm{ml}$. molten soft agar and plating as a soft agar layer according to the method described by Adams.

Preparation of toxin of Shigella dysenteriae. Organisms were grown in Neopeptone broth for $18 \mathrm{hr}$ at $37^{\circ}$, and were centrifuged at $3000 \mathrm{rev} . / \mathrm{min}$. for $20 \mathrm{~min}$. The sediment was resuspended in the casein hydrolysate (PGT) medium (de-ferrated) of Mueller \& Miller in the concentration to opacity reading 9. The bacterial suspension was shaken at $35^{\circ}$ for $18 \mathrm{hr}$ at low speed (100 strokes $/ \mathrm{min}$.), then centrifuged at $6000 \mathrm{rev} . / \mathrm{min}$. for $30 \mathrm{~min}$. in the cold $\left(4^{\circ}\right)$, and the supernatant fluid was filtered through a Selas filter (Selas Corporation of America, Dresher, Pennsylvania, U.S.A.). The filtrate was assayed for toxin by the agar-diffusion and floceulation methods.

Detection and assay of toxin. Detection of toxin was made by the agar-diffusion and the flocculation methods. Agar diffusion was particularly useful for the detection of specific antigen; $\mathrm{Lf}$ values of toxins were determined by flocculation.

Reference toxin. Purified Shiga neurotoxin was obtained from Dr W. E. van Heyningen of the Sir William Dunn School of Pathology, Oxford University. This toxin was used as a reference in the agar-diffusion and flocculation methods.

Antitoxin. The antitoxin used was refined dysentery antitoxin procured from Dr Mollie Barr of the Wellcome Research Laboratories, Beckenham, Kent, England; it contained 1400 units $/ \mathrm{ml}$. 


\section{RESULTS}

\section{Criterion for purity of toxin}

The difficulty of complete separation of exotoxin and endotoxin of Shigella dysenteriae has been the main cause of controversies. For this reason, the reference toxin of van Heyningen and toxins prepared in our laboratory were tested against refined dysentery antitoxin by the agar-diffusion method. Filter-paper discs (13 mm. diam.) were placed on the agar plate as shown in Fig. 1. Diluted refined dysentery antitoxin (0.05 ml., containing 28 units) was placed on the centre disc. Reference toxin from van Heyningen containing $2 \mathrm{Lf}$ units and toxins prepared in our Laboratory $(\mathbf{A}, \mathbf{B}, \mathbf{C})$ were placed on surrounding discs. The plates were sealed with adhesive tape and kept at $30^{\circ}$ for 2-3 days in a moist atmosphere. There were two precipitation lines between reference toxin and antitoxin; the inner line is later referred to as line 1 , and the outer line as line 2 . The refined antitoxin was then absorbed with $S$. dysenteriae organisms and tested against toxins by agar diffusion. After absorption of the antitoxin, only one precipitation line (line 1) was seen between reference toxin and absorbed antitoxin; line 2 had disappeared. It is apparent that the reference toxin contained two closely associated but different antigens, one having a common determinant with the somatic antigen, and the other being the neurotoxic antigen. Whether these two antigens were derived from a single large-molecule antigen or from a mixture of two distinct antigens is not known. However, further evidence indicates that these two antigens may be derived from a single large-molecule antigen. In the present paper, all determinations of neurotoxins are referred to line 1 between reference toxin and unabsorbed refined antitoxin.

\section{Toxin release by phage infection in Shigella dysenteriae}

Giant colonies of Shigella dysenteriae were grown on a tryptose agar plate incubated for $20 \mathrm{hr}$. One drop (0.03 ml.) of T-phage suspension containing $1 \times 10^{10}$ plaque-forming units (p.f.u.)/ml. was put on each giant colony. Reference toxin and antitoxin were then added on the discs before plates were sealed and kept at $30^{\circ}$ for 3-5 days for development of precipitation lines between antitoxin and phage-infected giant colonies. As can be seen from Fig. 2, phage-infected colonies released several kinds of macromolecules as well as neurotoxin.

\section{Toxin release in phage lysates of Shigella dysenteriae}

Shigella organisms grown in Neopeptone broth on a shaker at $37^{\circ}$ for $4 \mathrm{hr}$ in exponential phase were centrifuged down, washed with saline, and resuspended in PGT medium to an opacity reading of 5 . The bacterial suspensions in PGT medium were infected with $T$-phages at a ratio of $1: 5$, and shaken at $37^{\circ}$ for $1 \mathrm{hr}$. The lysed cultures were centrifuged for $30 \mathrm{~min}$. at $4^{\circ}$ and $9000 \mathrm{rev} . / \mathrm{min}$., and the supernatant fluids filtered through Selas filters. The filtrates were assayed for toxin by the agar-diffusion and flocculation methods. Bacterial suspensions without phage infection, as controls, were treated in the same way. The agar-diffusion plates showed that the neurotoxin (Fig. 1, line 1) of the reference toxin was further depolymerized into two smaller antigenic parts in the lysates. This indicated that the neurotoxin was an antigen of large molecular size which was further depolymerized 
by the phage-associated lysate enzymes. The amount of toxin contained in these lysates was determined by flocculation, with the results given in Table 1. It is apparent that neurotoxin was released from very young Shigella dysenteriae organisms by phage infection.

A

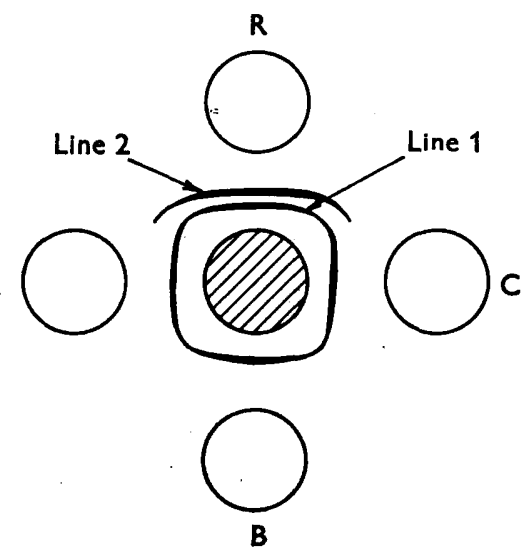

Fig. 1

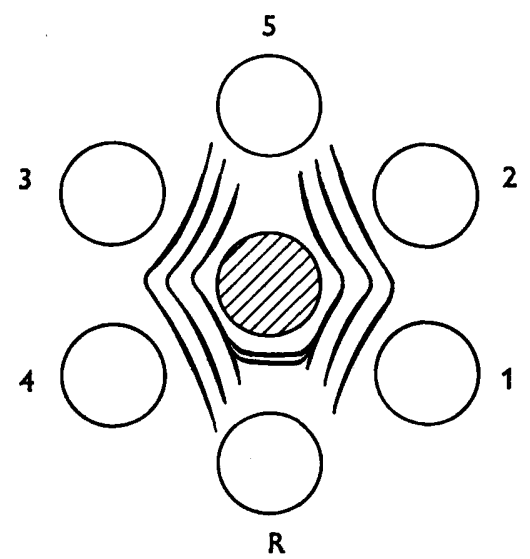

Fig. 2

Fig. 1. Precipitation reaction between antitoxin and toxin in agar plate. Centre disc contains antitoxin. Disc $R$ contains reference toxin. Discs A-C contain $0.1 \mathrm{ml}$. of toxins prepared in PGT medium.

Fig. 2. Precipitation reaction between phage-infected giant colonies of Shigella dysenteriae and antitoxin. Positions $1-4$ are giant colonies infected with phages $T_{1}, T_{3}, T_{5}, T_{6}$, respectively. Position 5 is uninfected colony. Centre disc contains antitoxin. $R$ disc contains reference toxin.

Table 1. Lf values of toxin in phage lysates of Shigella dysenteriae strains

\section{Lysates}

Strain 136-T + phage $\mathbf{T}_{1}$

Strain 186-o + phage $T_{1}$

Strain 186- $\mathbf{R}_{4}+$ phage $T_{7}$

Strain Sh $60+$ phage $T_{7}$

Strain 136-T without phage

Strain 136-o without phage

Strain 136-R $\mathbf{R}_{4}$ without phage

Strain Sh 60 without phage
Lf $/ \mathbf{m l}$.

15

20

20

25

Non-detectable

Non-detectable

Non-detectable

Non-detectable

\section{Preparation of phage-induced lysin and its activity}

Phage lysate was centrifuged at $\mathbf{3 0 0 0} \mathrm{rev} . / \mathrm{min}$. for $20 \mathrm{~min}$. and the supernatant fluid filtered through a Selas filter. The filtrate was ultracentrifuged in a Spinco Preparative Centrifuge at 40,000 rev./min. $(143,000 \mathrm{~g}$ maximum) for $4 \mathrm{hr}$. The phage in the supernatant fraction gave $4 \times 10^{4}$ p.f.u./ml., while the sedimented portion gave $2 \times 10^{10}$ p.f.u./ml. The activity of this crude endolysin on acetone-powder preparations was that the lysin effected $25 \%$ loss in turbidity of cell suspensions in $30 \mathrm{~min}$. at $30^{\circ}$. The rate of lysis of the Shigella organisms by this lysin preparation is shown in Fig. 3, which illustrates the linear relationship between endolysin concentration and rate of lysis of acetone-powder preparations of $S$. dysenteriae. 


\section{The effect of endolysin on toxin release from acetone-powder preparations of Shigella dysenteriae}

Acetone-powder preparations of Shigella dysenteriae were suspended in phosphate buffer ( $\mathrm{pH} 7 \cdot 0$ ) to an opacity reading of 15 . One ml. of endolysin preparation was added to $9.0 \mathrm{ml}$. of bacterial suspension; as a control $1 \mathrm{ml}$. of Neopeptone broth was added to $9.0 \mathrm{ml}$. of the bacterial suspension. These mixtures were incubated

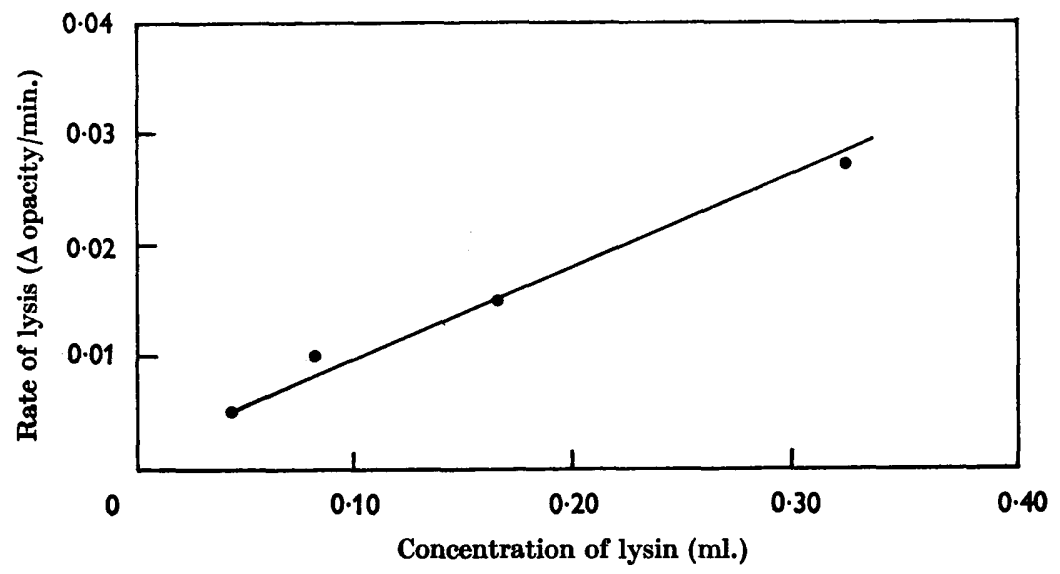

Fig. 8. Effect of lysin concentration on the rate of lysis of acetone-powder preparations of Shigella dysenteriae.

at $30^{\circ}$ for $40 \mathrm{~min}$., after which time the opacity readings were 10.0 and 13.4 , respectively. The decrease of turbidity with the endolysin lysate at $30^{\circ}$ in $40 \mathrm{~min}$. was about $25 \%$. These mixtures were centrifuged in the cold $\left(4^{\circ}\right)$ and the supernatant fluids assayed for toxin by the agar-diffusion and flocculation methods. The agar-diffusion plate showed that both the endolysin lysate and the phosphate buffer contained neurotoxin, as well as another non-specific antigen. The amounts of antigenic substance in the endolysin lysate and the phosphate buffer were both $30 \mathrm{Lf} / \mathrm{ml}$. It is apparent therefore that the endolysin did not have a direct effect on the amount of neurotoxin released from the acetone-powder preparations of organisms despite the lysis of $25 \%$ of the organisms. This suggests that the neurotoxin was not directly released from the cytoplasm but was probably released from the surface of the cell wall. Examination of the plate showed that lines 1 and 2 of the reference toxin joined into one line of antigen released in phosphate buffer; this suggests that two antigens in the reference toxin might be depolymerized from a single antigen of large molecular size released in phosphate buffer (Fig. 4).

\section{The effect of endolysin on living Shigella dysenteriae organisms}

An overnight culture of Shigella dysenteriae was centrifuged, the sedimented organisms washed with cold saline once, and resuspended in phosphate buffer $(\mathrm{pH} \mathrm{7.0)}$ to an opacity reading of 15 . One $\mathrm{ml}$. of endolysin preparation was added to $9.0 \mathrm{ml}$. of bacterial suspension; as a control $1 \mathrm{ml}$. of Neopeptone broth was added to $9.0 \mathrm{ml}$. of bacterial suspension. These mixtures were incubated at $30^{\circ}$ 
for $40 \mathrm{~min}$., then centrifuged at $4^{\circ}$, and the supernatant fluids assayed for toxin. No significant changes of the opacity reading were noticed, and no toxin was detectable, either by the agar-diffusion method or by the flocculation method. The results indicate that the endolysin was not effective in releasing toxin from living Shigella dysenteriae organisms.

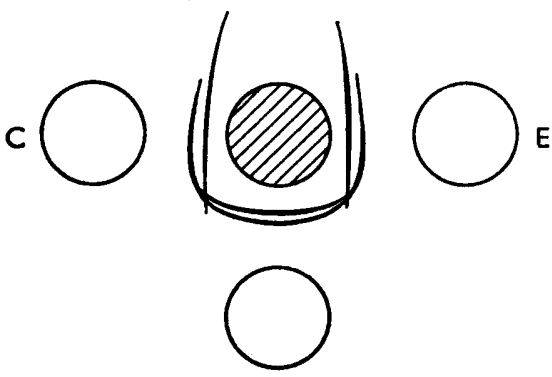

$\mathbf{R}$

Fig. 4. Precipitation lines of endolysin lysate. Disc E contains $0 \cdot 1 \mathrm{ml}$. of supernatant fluid of bacteria treated by endolysin. Disc C contains $0 \cdot 1 \mathrm{ml}$. of supernatant of bacteria suspended in buffer. Dise $R$ and centre disc contain reference toxin and antitoxin respectively.

\section{DISCUSSION}

Much has been written about the conditions for neurotoxin formation by Shigella dysenteriae, but there is no clear view about the mechanism of liberation of Shiga neurotoxin from the organisms. Thus it was interesting to see whether phage and phage-associated lysin in Shigella lysates might play some role in toxin release.

In the present work when Shigella dysenteriae and T-phages were brought together to produce infection and lysis, various kinds of biologically active macromolecules were released, including neurotoxin. Also, when $S$. dysenteriae organisms in a 4-hr culture were exposed to the action of a T-phage for $1 \mathrm{hr}$, only neurotoxin and its closely associated antigens were released into the supernatant medium. Neurotoxin released under this condition seems to be depolymerized, by phagebound enzyme, from a single large-molecule antigen ordinarily extractable into phosphate buffer. The phage-bound enzyme or enzymes involved in this process are probably held within the phage, for the reason that lysate containing phageinduced lysin (endolysin) does not have the activity of depolymerizing neurotoxin. It is conceivable that the phage-bound enzyme may activate an autolytic enzyme or inhibit a depressor of an autolytic enzyme.

The endolysin, when incubated with acetone-powder preparations of Shigella dysenteriae at $30^{\circ}$, effected lysis of $25 \%$ of the organisms in 30 min. The lysates contained neurotoxin; however, there was no difference in the amount of neurotoxin released under the effect of endolysin and that released into the phosphate buffer control from the acetone-powder preparations. This indicates that neurotoxin was not directly released from cytoplasm but rather released from the cell wall surface. Additional evidence for this idea is that, after the extraction of neurotoxin from acetone-powder preparations of $\boldsymbol{S}$. dysenteriae, the opacity readings of the suspensions remained unchanged, and the organisms retained the normal shape of Gram- 
negative rods when viewed in the microscope. Living organisms of growing $S$. dysenteriae suspended in phosphate buffer did not release detectable neurotoxin after incubation at $30^{\circ}$ for $40 \mathrm{~min}$. These findings suggest that the linkage between the neurotoxin and the cell wall is firm in actively growing organisms but, when these are dead (as in the acetone-powder preparations), the linkage is easily broken in phosphate buffer, probably because of the activity of some surface-attacking autolytic enzyme.

The author thanks Dr W. L. Barksdale for helpful advice and discussion, and is grateful to Mr R. Rivera, Miss S. Herbst and Mr E. Lyle for their technical assistance. He is also grateful to Miss Suzanne Li for her line drawings. The main part of this work was supported by grant AI-04187 of the National Institute of Allergy and Infectious Diseases, U.S. Public Health Service.

\section{REFERENCES}

Adams, M. H. (1959). Bacteriophages. New York: Academic Press.

Barksdale, W. L. \& Pappenheimer, A. M. (1954). Phage-host relationships in nontoxigenic and toxigenic diphtheria bacilli. J. Bact. 67, 220.

Borvin, A. (1940). Les deux toxines du bacille de Shiga et leur place dans la classification générale des toxines bactériennes. Revue Immunol. Thér. antimicrob. 6, 86.

Dubos, R. \& Geiger, J. W. (1946). Preparation and properties of Shiga toxin and toxoid. J. exp. Med. 84, 143.

Engley, F. B., Jun. (1952). The neurotoxin of Shigella dysenteriae. Bact. Rev. 16, 153.

LI, K., Barksdale, W. L. \& Garmise, L. (1961). Phenotypic alterations associated with bacteriophage carrier state of Shigella dysenteriae. J. gen. Microbiol. 24, 355.

Mueller, J. H. \& Mrluer, P. A. (1941). Production of diphtheric toxin of high potency (100 Lf) on a reproducible medium. J. Immun. 40, 21.

ŠureK, J. \& RAšKa, K. JR. (1963). A contribution to the study of Shigella dysenteriae toxins. J. Hyg. Epidem. Microbiol. Immun. 7, 46.

Van Heyningen, W. E. \& Gradstone, G. P. (1953). The neurotoxin of Shigella shigae. 1. Production, purification and properties of the toxin. Br. J. exp. Path. 34, 202. 